\title{
The Effect of Carvedilol on B-Type Natriuretic Peptide and Cardiac Function in Patients with Heart Failure and Persistent Atrial Fibrillation
}

\author{
Aleem U. Khand ${ }^{a}$ b Pei G. Chew ${ }^{a}$ Homeyra Douglas ${ }^{a}$ Julia Jones ${ }^{a}$ \\ Aftab Jan ${ }^{\mathrm{b}}$ J.G.F. Cleland ${ }^{\mathrm{c}}$ \\ a University Hospital Aintree NHS Trust, and ${ }^{\mathrm{b}}$ Liverpool Heart and Chest Hospital, Liverpool, and ${ }^{\mathrm{C}}$ Imperial College, \\ London, UK
}

\section{Key Words}

Atrial fibrillation $\cdot$ Heart failure $\cdot$ Natriuretic peptides

\begin{abstract}
Objectives: We sought to determine the relationship between changes in natriuretic peptides and symptoms as a consequence of introducing beta-blocker therapy, in patients with chronic heart failure (CHF) and persistent atrial fibrillation (AF). Methods: In a randomised, double-blind, placebo-controlled study involving 47 patients with $\mathrm{CHF}$ and persistent AF (mean age 68 years and $62 \%$ men), we analysed the individual change $(\Delta)$ in B-type natriuretic peptide (BNP) level to the introduction of carvedilol (titrated to a target dose of $25 \mathrm{mg}$ twice daily, group A) or placebo (group B) in addition to background treatment with digoxin. Symptoms score, 6-min walk distance, New York Heart Association (NYHA) class, left ventricular ejection fraction (LVEF), heart rate (24-hour ECG) and BNP were measured at baseline and at 4 months. Results: $\operatorname{LVEF}(\Delta$ median +5 vs. $+0.4, \mathrm{p}=0.048)$, symptoms score ( $\Delta$ median -4 vs. $0, \mathrm{p}=$ $0.04)$, NYHA class ( $\triangle$ median $-33 \%$ vs. $+3 \%$ in NYHA class $3-4$, $\mathrm{p}=0.046$ ) and heart rate $[\Delta$ median 24 -hour ventricular rate (VR) -19 vs. $-2, p<0.0001$ ] improved with combination therapy of digoxin and carvedilol compared to digoxin alone, but BNP ( $\Delta$ median +28 vs. $-6, p=0.11$ ) trended in the opposite direction. There was no relationship between the degree of symptomatic improvement or VR control and BNP
\end{abstract}

response. Conclusion: After the introduction of carvedilol, clinical outcome appears unrelated to BNP changes in patients with $\mathrm{CHF}$ and AF. Changes in BNP cannot be used as a marker of clinical response in terms of symptoms or cardiac function in this setting.

(c) 2015 S. Karger AG, Basel

\section{Introduction}

Beta-blockers are an established treatment in chronic heart failure (CHF) due to left ventricular (LV) systolic function, with evidence of both an improvement in symptoms and prognosis [1-4]. The prevalence of atrial fibrillation (AF) varies with the severity of heart failure $(\mathrm{HF})[5$, 6] and is the predominant rhythm in up to $34 \%$ of hospitalised CHF patients [7]. The landmark CHF beta-blocker studies included relatively few patients with AF. There is some evidence that the benefits of beta-blockers extend to patients with AF and heart failure $[8,9]$ although 1 metaanalysis of AF subsets in HF trials (mostly with beta-1 selective beta-blockers) suggested no survival benefit [10].

Natriuretic peptides are an important diagnostic aid, allied to clinical assessment, where there is still uncertainty as to the cause of breathlessness [11]. However, their value in titrating $\mathrm{HF}$ therapy, beyond intensive clinical management, is still under debate [12]. The evidence is mixed, with both positive [13-16] and negative studies [17-19], al-

\section{KARGER 125}

(C) 2015 S. Karger AG, Basel

$0008-6312 / 15 / 1303-0153 \$ 39.50 / 0$ 
though there is an emerging pattern of improved outcome in younger patients ( $<75$ years of age) [19]. There is evidence of a reduction [20-22] in natriuretic peptide levels in HF patients with sinus rhythm on beta-blocker therapy, but this is not uniform $[23,24]$. Some analyses $[21,23]$ were confounded by dosage changes in other vasodilating HF medication. In the context of CHF patients with persistent $\mathrm{AF}$, there is limited evidence and, more specifically, no randomised, control group trial data on how B-type natriuretic peptide (BNP) responds to the introduction of betablockers in a population of stable HF patients. One post hoc study suggested a more marked reduction of BNP in CHF patients with AF as opposed to sinus rhythm [25]. Amelioration of adverse remodelling of the heart, attenuation of neuro-humoral activation together with improved ventricular rate $(\mathrm{VR})$ control are potential mechanisms by which beta-blockers reduce natriuretic peptides in patients with $\mathrm{CHF}$ and persistent $\mathrm{AF}$ [26]. We sought to analyse the response of $\mathrm{BNP}$ in $\mathrm{HF}$ patients with persistent $\mathrm{AF}$, to the introduction of carvedilol, a vasodilating, non-selective beta-blocker, and to explore the relationship of BNP response and clinical outcome on an individual patient level.

\section{Methods}

This was a post hoc analysis of data from the Carvedilol Atrial Fibrillation Evaluation (CAFÉ) study; details of the methods are as described previously [9]. In summary, this was a randomised, double-blind, placebo-controlled, parallel-arm study of carvedilol and digoxin combination therapy versus digoxin alone and carvedilol versus digoxin alone in patients with persistent $A F(>1$ month) and CHF. Criteria for the definition of HF included both appropriate symptoms of HF for $>2$ months and echocardiographic evidence of cardiac dysfunction [LV ejection fraction (LVEF) $<40 \%$ or preserved LV systolic function together with LV hypertrophy suggesting diastolic dysfunction in the absence of an alternative potential cause of symptoms].

Investigations were performed at baseline and at 4 months after the introduction and up-titration of carvedilol or placebo. Before randomisation, patients had their digoxin dose increased, if necessary, to achieve an optimal resting VR control (defined as a VR of at least $<90 \mathrm{bpm}$ on 12-lead ECG). Plasma concentrations of digoxin were monitored to avoid toxicity. Forty-seven patients were randomised into 2 groups: 24 in the carvedilol-treated group and 23 in the placebo group. Both groups continued on open-label digoxin, with 1 group receiving double-blind carvedilol and the other receiving double-blind placebo. The starting dose of carvedilol was $3.125 \mathrm{mg}$ twice daily (b.d.) and this was increased at 2-week intervals to the target dose of $25 \mathrm{mg}$ (an up-titration period of 2 months) or $50 \mathrm{mg}$ b.d. for patients weighing $>85 \mathrm{~kg}$. The following treatments were assessed: digoxin alone versus the combination of digoxin and carvedilol over 4 months (phase 1) and digoxin alone versus carvedilol alone over 6 months (phase 2; fig. 1). Withdrawing digoxin at the same time as initiating and up-titrating be-

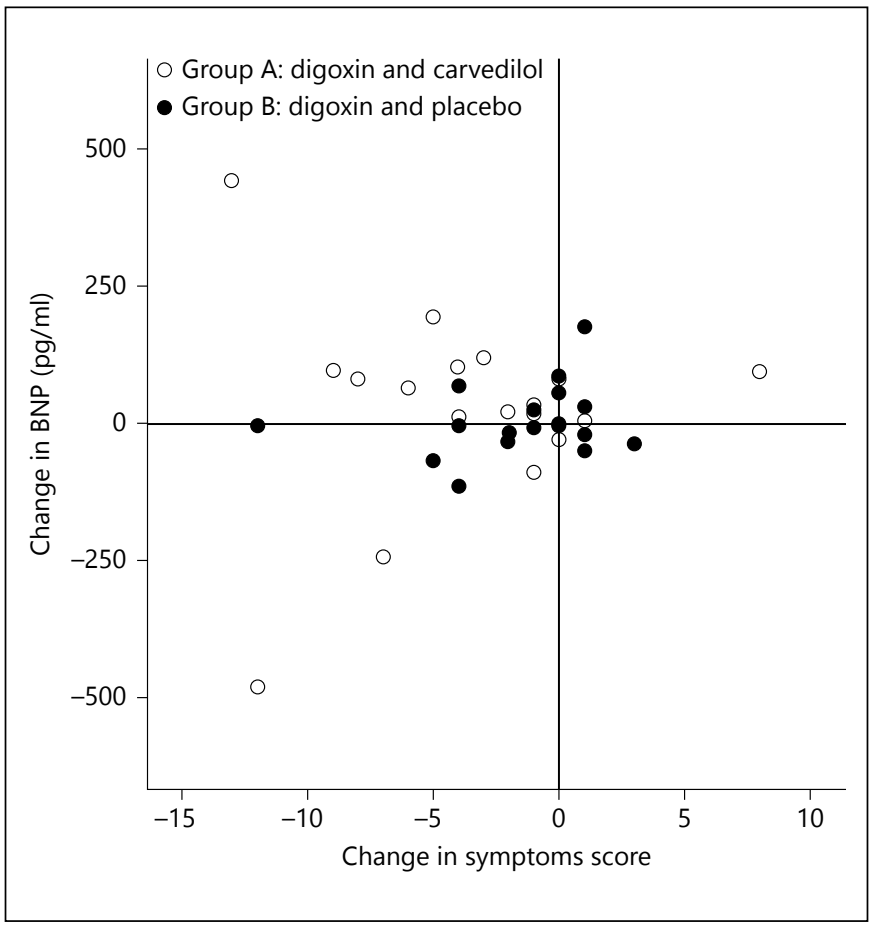

Fig. 1. Change in BNP against change in symptoms score $(n=41)$.

ta-blockers could increase the risk of worsening HF. Therefore, a complex study design was adopted to allow double-blind initiation of carvedilol first, followed by double-blind withdrawal of digoxin once the maintenance doses of carvedilol had been achieved.

Investigations were performed at baseline and after each phase, i.e. at 4 and 6 months. We restricted our analyses to the first phase of the study in order to understand the BNP response to carvedilol therapy and to understand its relationship to the clinical outcome.

\section{Blood Tests}

BNP samples were taken in the morning (between 9 a.m. and midday) after 20 min of rest in a semi-recumbent state. Blood samples were collected into EDTA tubes, the sample was placed immediately on ice, centrifuged for $30 \mathrm{~min}$ at $4^{\circ} \mathrm{C}$, and the plasma was stored at $-80^{\circ} \mathrm{C}$ before assay. Assay standard or extract ( 100 $\mu \mathrm{l})$ was added to assay tubes plus $100 \mu \mathrm{l}$ of BNP anti-serum (Peninsula Laboratories, San Carlos, Calif., USA).

\section{Statistics}

For each patient, the change from baseline for the results of investigations was determined at the end of phase 1 ( 4 months) and phase 2 (6 months). The change from baseline (i.e. prior to the first randomisation) was then compared between groups. A paired Student $t$ test for intra-group comparisons and a 2-sided t test for between-group comparisons for normally distributed data. The Mann-Whitney U test was used to compare differences for nonparametric data. For paired-sample non-normal data, the Wilcoxon signed rank test was used. The $\mathrm{Z}$ test was used for the comparison of proportions where appropriate. A value of $\mathrm{p}<0.05$ denoted statistical significance. 
Table 1. Population characteristics at baseline

\begin{tabular}{|c|c|c|c|}
\hline & Group A & Group B & $\mathrm{p}$ value \\
\hline $\mathrm{n}$ & 24 & 23 & \\
\hline Age & $68.6 \pm 9.4$ & $68.4 \pm 9.8$ & NS \\
\hline Men, $\mathrm{n}$ & 14 & 15 & NS \\
\hline IHD aetiology, $\mathrm{n}$ & 8 & 11 & NS \\
\hline Duration of AF, weeks (median, IQR) & $72(23,203)$ & $52(16,156)$ & NS \\
\hline Previous cardioversion attempts, $\mathrm{n}$ & $0.3 \pm 0.6$ & $0.7 \pm 1.7$ & NS \\
\hline Resting ECG heart rate & $89 \pm 25$ & $82 \pm 19.7$ & NS \\
\hline LVEF, \% & $24 \pm 13.4$ & $24.7 \pm 9.2$ & NS \\
\hline LVEDD, mms & $53 \pm 10.4$ & $54.2 \pm 9.7$ & NS \\
\hline LA size, $\mathrm{mms}$ & $49 \pm 8.3$ & $47.9 \pm 8.0$ & NS \\
\hline \multicolumn{4}{|l|}{ NYHA class, $\mathrm{n}$} \\
\hline $\mathrm{I}$ & 1 & 1 & NS \\
\hline II & 11 & 16 & \\
\hline III & 9 & 6 & \\
\hline IV & 3 & 0 & \\
\hline Digoxin dose, mg & $0.25 \pm 0.11$ & $0.24 \pm 0.1$ & NS \\
\hline Digoxin plasma concentration, $\mathrm{nmol} / \mathrm{l}$ & $1.6 \pm 0.8$ & $1.5 \pm 0.7$ & NS \\
\hline ACE inhibitor, n (\%) & $17(71)$ & $16(71)$ & NS \\
\hline Anticoagulated, n (\%) & $19(79)$ & $19(83)$ & NS \\
\hline
\end{tabular}

Results in mean \pm SD (except where stated). VR = Ventricular rate; LVEF = left ventricular ejection fraction; $\mathrm{BNP}=$ plasma brain natriuretic peptide levels; NYHA = New York Heart Association functional class Heart failure; IQR = interquartile range.

\section{Investigations}

We assessed LVEF by ECG-gated radionuclide ventriculography and VR control by 24-hour ambulatory ECG. We also investigated exercise tolerance by the 6-min corridor walk distance in all patients. Plasma concentrations of BNP (C-terminal, Peninsular Laboratories, San Carlos, Calif., USA) were measured at baseline and at 4 months.

\section{Assessment of Symptoms}

We used a self-administered, quantitative questionnaire designed to measure a patient's perception of the frequency and severity of symptoms and their functional capacity. A 4 -point scale $(0=$ absent, 3 = severe symptoms) was used for the following symptoms: chest pain/discomfort, fatigue, shortness of breath and palpitations. For the first 3 symptoms, patients were asked to grade severity at rest, during walking at a normal pace and whilst climbing stairs. We also asked about the patient's 'global' health or their sense of wellbeing. The responses were summed to produce a symptoms score ranging from 0 (no symptoms) to 33 (worst symptoms).

\section{Results}

Table 1 defines the patient population in the trial. All but 3 patients were titrated to a target dose of carvedilol $25 \mathrm{mg}$ b.d., 2 were titrated to $12.5 \mathrm{mg}$ b.d. and 1 to $6.25 \mathrm{mg}$ b.d. The cause of not achieving the target dose was symp- tomatic hypotension. No patient reverted to sinus rhythm during the trial.

Changes from baseline for the 24-hour mean heart rate, systolic blood pressure and 6-min walk distance were considered normally distributed data whereas changes from baseline for LVEF, symptoms score and BNP were non-normal data and are analysed as such.

Twenty of 24 patients randomized to carvedilol (group A) and 21 of 23 patients randomized to placebo (group B) completed phase 1 . Three patients withdrew due to adverse effects subsequent to the initiation of carvedilol (1 each with gastrointestinal disturbance, tiredness and bronchospasm) and 1 withdrew in the placebo group (self-withdrawal). The mean daily dose of carvedilol achieved in group A was $47.6 \mathrm{mg}$. Plasma digoxin concentration did not differ significantly between groups either at baseline (table 1) or at the end of phase 1 ( $1.2 \pm 0.5 \mathrm{vs}$. $1.4 \pm 0.5 \mathrm{nmol} / \mathrm{l}$ with digoxin alone and in combination, respectively, $\mathrm{p}=0.2$ ). However, 2 patients on carvedilol developed possible symptoms of digoxin toxicity and had their digoxin dose reduced although serum concentrations remained in the therapeutic range.

Of the 23 patients in group $\mathrm{A}$, none deteriorated with acute decompensation of $\mathrm{CHF}$ upon introduction of 
Table 2. The effect of carvedilol on clinical outcome and BNP levels in patients with HF and persistent AF

\begin{tabular}{lcllll}
\hline & $\begin{array}{l}\text { Group A at } \\
\text { baseline } \\
(\mathrm{n}=24)\end{array}$ & $\begin{array}{l}\text { Group B at } \\
\text { baseline } \\
(\mathrm{n}=23)\end{array}$ & $\begin{array}{l}\text { Group A, } \\
\Delta \text { median }\end{array}$ & $\begin{array}{l}\text { Group B, } \\
\Delta \text { median }\end{array}$ & p value \\
\hline 24-hour mean VR & 82 & 76 & -19 & -2 & $<0.0001$ \\
LVEF & $24 \%$ & $24.7 \%$ & +5.3 & +0.4 & 0.048 \\
Symptoms score & 12 & 9 & -4 & 0.00 & 0.04 \\
6-MWD, m & 353 & 354 & +26.00 & +40 & 0.60 \\
Median BNP, pg/ml & 86 & 122 & +28 & -6 & 0.11 \\
NYHA class III and IV & $50 \%$ & $26 \%$ & -33 & +3 & 0.046 \\
\hline
\end{tabular}

MWD = Minute walk distance.

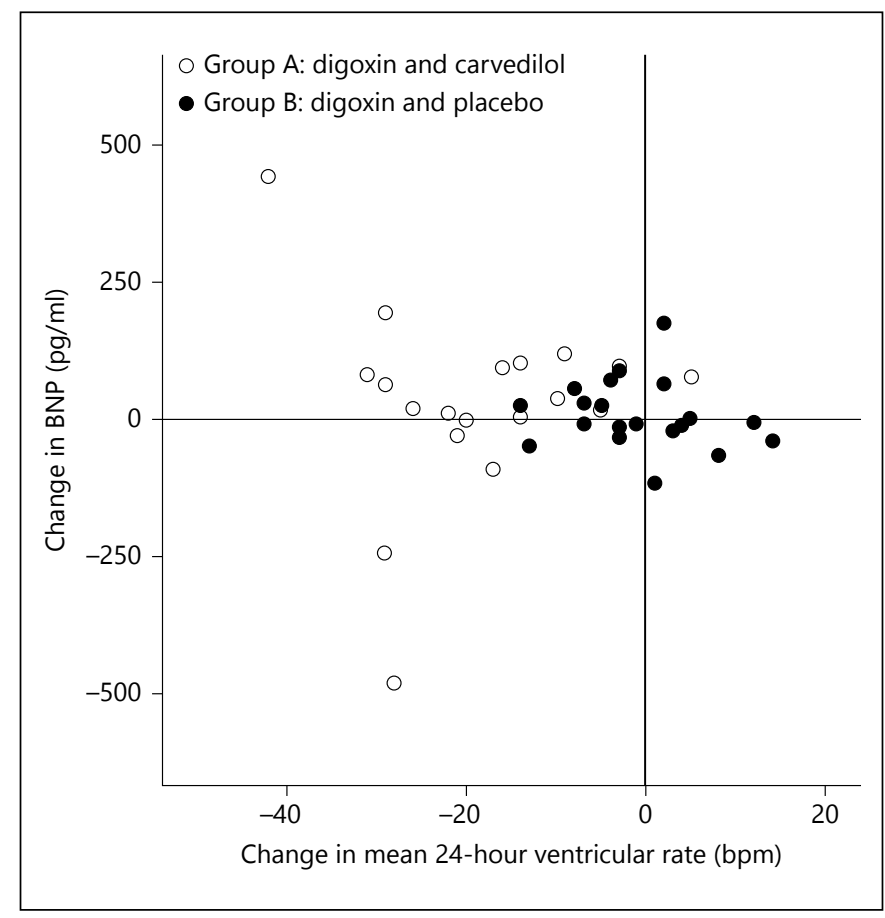

Fig. 2. Change in BNP plotted against change in 24-hour mean VR $(\mathrm{n}=41)$.

carvedilol. There was a consistent improvement in all parameters studied, including LVEF, symptoms score, New York Heart Association (NYHA) class, VR control and VR control during sub-maximal exercise (table 2). However, the 6-min walk distance did not change between groups. Figure 1 is a scatterplot of individual change $(\Delta)$ in BNP and $\Delta$ symptoms score for all 41 patients, categorised by treatment allocation, who completed this phase of the study. Figure 2 is a scatterplot of $\triangle$ BNP to $\Delta$ mean 24-hour VR, categorised by treatment allocation.
There was no correlation or pattern of BNP response to change in LVEF, symptoms (either measured by symptom questionnaire or NYHA class HF status) or 24-hour mean VR. Despite the improvement in clinical parameters, BNP did not change significantly, on either an individual basis or when the change from baseline was compared between groups (table 2).

\section{Discussion}

As far as we are aware, there are no published data on the effect of beta-blockers on BNP in patients with stable $\mathrm{HF}$ and persistent AF from a registry or epidemiological study. Previous analysis of this HF population was hampered by the lack of a control population as well as the potential confounding effect of alteration of vasodilating drugs or diuretics during up-titration with beta-blockers $[21,25]$.

In this post hoc analysis of the CAFÉ trial we have demonstrated that carvedilol, a vasodilating beta-blocker, does not predictably reduce plasma BNP in CHF and AF. This is despite the improvement in a number of parameters that would indicate a reduction in LV filling pressures.

There is individual variability in BNP levels, affected by gender, age and renal function [26]. This variation challenges arbitrary cut-off points for diagnosis or monitoring. We therefore investigated, on an individual patient basis, the pattern of BNP response (change of BNP from baseline) to carvedilol therapy in HF in order to gain insight into neuro-humoral changes in $\mathrm{CHF}$ and persistent AF during beta-blocker therapy. Such an insight can be reliably gained by serial measurement and in the context of a control population with 'intensive' monitoring 
and medical management (patients were reviewed on a fortnightly basis during up-titration).

Our results suggest that BNP cannot be used as a marker of clinical response or no response in patients with $\mathrm{CHF}$ and AF who are on beta-blockers. Davis et al. [24], in an elegant study of stable, mild HF patients described both a probable increased production and a reduced clearance of natriuretic peptides with the introduction of metoprolol, suggesting natriuretic 'enhancement' as a possible mode of action of the beta-blockers. A retrospective analysis by Luchner et al. [27] also suggested this as a possibility. The use of a vasodilating beta-blocker as opposed to metoprolol, in the study by Davis et al. [24], may theoretically have greater potential to reduce BNP due to the reduction of afterload and LV wall stress. One explanation is that reduced excretion could be counterbalanced with reduced feedback stimuli for the production of BNP as a consequence of lowering blood pressure. However, the mean $( \pm \mathrm{SD})$ systolic blood pressure with carvedilol was $121 \pm 24 \mathrm{~mm} \mathrm{Hg}$, which was not different to placebo (group B, $134 \pm 20 \mathrm{~mm} \mathrm{Hg}, \mathrm{p}=$ n.s.).

Konishi et al. [21] demonstrated a marked reduction of BNP with either bisoprolol or carvedilol administration in patients with CHF in AF; however, this was a retrospective analysis with variable co-administration of angiotensin-converting enzyme inhibitors and diuretics, which is likely to have confounded the results. Most of the patients also had preserved LV systolic function. In this study, that concerns stable HF patients with persistent $\mathrm{AF}$, there was a reduction in digoxin dose in only 2 patients, due to unfounded fears of digoxin toxicity. There was no change in diuretic or vasodilator dosage during this phase of the trial.

It is possible that the lack of consistent reduction in BNP could be secondary to the timing of sampling. At least 2 studies have described a bi-phasic response with an initial rise followed by a fall in BNP over a year $[21,28]$.

This study stands in contrast to that by Hartmann et al. [22]. These authors analysed a subset of European patients in the Carvedilol Prospective Randomized Cumulative Survival (COPERNICUS) study of stable but severe HF (LVEF <25\%). The proportion of patients with AF was not stated. Beyond the first month, in which there was a slight increase in BNP, there was a significant and gradual decrease in BNP to the end of the study. However, the numbers at the end were significantly reduced, due to a lack of samples, mortality or events which could have influenced the analysis by 'natural selection'. The influence of AF alone on BNP in the absence of HF [29] and the mechanism of a lack of reduction in BNP with beta-blocker therapy in HF and persistent AF merit further study. One study of natriuretic physiology suggested that BNP may also be secreted by the atrium and that this diminishes significantly with successful cardioversion [30]. A number of studies have suggested that changes in natriuretic peptide levels during CHF treatment and the final values pre-discharge can have a considerable prognostic impact [31]. Our analysis suggests that AF complicates the relationship between HF treatment and BNP response and that prognostication or titration of medical therapy with serial BNPs in this population is not feasible.

\section{Limitations}

There was a mixed population of ischaemic and nonischaemic cardiomyopathies and insufficient numbers to explore differences in aetiology and BNP response. There were also insufficient numbers to investigate the relationship between serial change in BNP in this population and hard end points such as death or cardiac transplantation. The median values of BNP at baseline were lower than in other trials treating HF patients; this could obscure an effect of consistent BNP reduction with beta-blocker treatment in 'sicker' populations with higher BNP values. In patients with a BNP level $>150 \mathrm{pg} / \mathrm{ml}$ who were administered carvedilol, the median change was -3 with a range of -480 to +442 , revealing a considerable response heterogeneity (comparative figures for placebo: median change -34 , range -116 to +175 ).

\section{Conclusion}

After the introduction of carvedilol, the clinical outcome in patients with $\mathrm{HF}$ and persistent $\mathrm{AF}$ is not related to BNP. Changes in BNP cannot be used as a marker of clinical response in terms of symptoms or cardiac function in this setting.

References

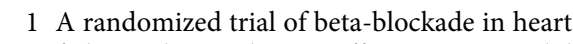
failure. The Cardiac Insufficiency Bisoprolol Study (CIBIS). CIBIS Investigators and Committees. Circulation 1994;90:1765-1773.

-2 Effects of carvedilol, a vasodilator beta-blocker, in patients with congestive heart failure due to ischaemic heart disease. Australia-New Zealand Heart Failure Research Collaborative Group. Circulation 1995;92:212-218.

-3 Randomised, placebo-controlled trial of carvedilol in patients with congestive heart failure due to ischaemic heart disease. Australia/ New Zealand Heart Failure Research Collaborative Group. Lancet 1997;349:375-380.
} 
-4 Packer M, Bristow MR, Cohn JN, Colluci WS, Fowler MB, Gilbert EM, Shusterman NH: The effect of carvedilol on morbidity and mortality in patients with chronic heart failure. US Carvedilol Heart Failure Study Group. N Engl J Med 1996;334:1349-1355.

5 Khand AU, Rankin AC, Kaye G, Cleland JGF: Systematic review of the management of atrial fibrillation in patients with heart failure. Eur Heart J 2000;21:614-632.

6 Khand AU, Cleland JGF, Deedwania PC: Prevention of and medical therapy for atrial arrhythmias in heart failure. Heart Fail Rev 2002;7:267-283.

7 Jones JD, Khand AU, Douglas H, Ashrafi R, Shaw M, Cleland JG: The intersection of atrial fibrillation and heart failure in a hospitalised population. Acta Cardiol 2013;68:395402.

8 Joglar JA, Acusta AP, Schusterman NH, Ramaswamy K, Kowal R, Barbera SJ, et al: Effect of carvedilol on survival and hemodynamics in patients with atrial fibrillation and left ventricular dysfunction: retrospective analysis of the US Carvedilol Heart Failure Trials Program. Am Heart J 2001;142:498-501.

$\checkmark 9$ Khand AU, Rankin AC, Martin W, Taylor J, Gemmell I, Cleland JG: Carvedilol alone or in combination with digoxin for the management of atrial fibrillation in patients with heart failure? J Am Coll Cardiol 2003;42: 1944-1951.

10 Rienstra M, Damman K, Mulder BA, Van Gelder IC, Mcmurray JJ, Van Veldhuisen DJ: Beta-blockers and outcome in heart failure and atrial fibrillation: a meta-analysis. JACC Heart Fail 2013;1:21-28.

11 Maisel AS, McCord J, Nowak RM, Hollander JE, Wu AH, Duc P, Omland T, Storrow AB, Krishnaswamy P, Abraham WT, Clopton P, Steg G, Aumont MC, Westheim A, Knudsen CW, Perez A, Kamin R, Kazanegra R, Herrmann HC, McCullough PA: Bedside B-type natriuretic peptide in the emergency diagnosis of heart failure with reduced or preserved ejection fraction. Results from the Breathing Not Properly Multinational Study. J Am Coll Cardiol 2003;41:2010-2017.

12 Porapakkham P, Porapakkham P, Zimmet H, Billah B, Krum H: B-type natriuretic peptideguided heart failure therapy: a meta-analysis. Arch Intern Med 2010;170:507-514.

-13 Troughton RW, Frampton CM, Yandle TG, Espiner EA, Nicholls M: Treatment of heart failure guided by plasma aminoterminal natriuretic peptide (N-BNP) concentrations. Lancet 2000;355:1126-1130.

14 Jourdain P, Jondeau G, Funck F, Gueffet P, Le HA, Donal E, Aupetit JF, Aumont MC, Galinier M, Eicher JC, Cohen-Solal A, Juilliere Y: Plasma brain natriuretic peptide-guided therapy to improve outcome in heart failure: the STARS-BNP Multicenter Study. J Am Coll Cardiol 2007;49:1733-1739.
15 Januzzi JL Jr, Rehman SU, Mohammed AA, Bhardwaj A, Barajas L, Barajas J, Kim HN, Baggish AL, Weiner RB, Chen-Tournoux A, Marshall JE, Moore SA, Carlson WD, Lewis GD, Shin J, Sullivan D, Parks K, Wang TJ, Gregory SA, Uthamalingam S, Semigran MJ: Use of amino-terminal pro-B-type natriuretic peptide to guide outpatient therapy of patients with chronic left ventricular systolic dysfunction. J Am Coll Cardiol 2011;58: 1881-1889.

16 Berger R, Moertl D, Peter S, Ahmadi R, Huelsmann M, Yamuti S, Wagner B, Pacher R: Nterminal pro-B-type natriuretic peptideguided, intensive patient management in addition to multidisciplinary care in chronic heart failure: a 3-arm, prospective, randomized pilot study. J Am Coll Cardiol 2010;55: 645-653.

17 Shah MR, Califf RM, Nohria A, Bhapkar M, Bowers M, Mancini DM, Fiuzat M, Stevenson LW, O'Connor CM: The STARBRITE trial: a randomized, pilot study of B-type natriuretic peptide-guided therapy in patients with advanced heart failure. J Card Fail 2011;17:613621.

18 Pfisterer M, Buser P, Rickli H, Gutmann M, Erne P, Rickenbacher P, Vuillomenet A, Jeker U, Dubach P, Beer H, Yoon SI, Suter T, Osterhues HH, Schieber MM, Hilti P, Schindler R, Brunner-La Rocca HP: BNP-guided vs symptom-guided heart failure therapy: the Trial of Intensified vs. Standard Medical Therapy in Elderly Patients with Congestive Heart Failure (TIME-CHF) randomized trial. JAMA 2009;301:383-392.

19 Lainchbury JG, Troughton RW, Strangman KM, Frampton CM, Pilbrow A, Yandle TG, Hamid AK, Nicholls MG, Richards AM: Nterminal pro-B-type natriuretic peptideguided treatment for chronic heart failure: results from the BATTLESCARRED (NTproBNP-Assisted Treatment to Lessen Serial Cardiac Readmissions and Death) trial. J Am Coll Cardiol 2009;55:53-60.

20 Kawai K, Hata K, Takaoka H, Kawai H, Yokoyama M: Plasma brain natriuretic peptide as a novel therapeutic indicator in idiopathic dilated cardiomyopathy during beta-blocker therapy: a potential of hormone-guided treatment. Am Heart J 2001;141:925-932.

21 Konishi M, Haraguchi G, Kimura S, Inagaki $\mathrm{H}$, Kawabata M, Hachiya $\mathrm{H}$, Hirao K, Isobe $\mathrm{M}$ : Comparative effects of carvedilol vs. bisoprolol for severe congestive heart failure. Circ J 2010;74:1127-1134.
22 Hartmann F, Packer M, Coats AJ, Fowler MB, Krum H, Mohacsi P, Rouleau JL, Tendera M, Castaigne A, Trawinski J, Amann-Zalan I, Hoersch S, Katus HA: NT-proBNP in severe chronic heart failure: rationale, design and preliminary results of the COPERNICUS NTproBNP substudy. Eur J Heart Fail 2004;6: 343-350.

23 Yoshizawa A, Yoshikawa T, Nakamura I, Satoh T, Moritani K, Suzuki M, Baba A, Iwanaga S, Mitamura H, Ogawa S: Brain natriuretic peptide response is heterogeneous during beta-blocker therapy for congestive heart failure. J Card Fail 2004;10:310-315.

24 Davis ME, Richards AM, Nicholls MG, Yandle TG, Frampton CM, Troughton RW: Introduction of metoprolol increases plasma B-type cardiac natriuretic peptides in mild, stable heart failure. Circulation 2006;113: 977-985.

25 Meng F, Yoshikawa T, Baba A, Moritani K, Suzuki M, Satoh T, et al: Beta-blockers are effective in congestive heart failure patients with atrial fibrillation. J Card Fail 2003;9:398-403.

-26 Januzzi JL Jr: The role of natriuretic peptide testing in guiding chronic heart failure management: review of available data and recommendations for use. Arch Cardiovasc Dis 2012;105:40-50.

27 Luchner A, Burnett JC Jr, Jougasaki M, Hense HW, Riegger GA, Schunkert H: Augmentation of the cardiac natriuretic peptides by beta-receptor antagonism: evidence from a population-based study. J Am Coll Cardiol 1998; 32:1839-1844.

28 Sanderson JE, Chan WW, Hung YT, Chan SKW, Shum IOL, Raymond K, Woo KS: Effect of low dose betablockers on atrial and ventricular (B type) natriuretic factor in heart failure: a double blind, randomised comparison of metoprolol and a third generation vasodilating betablocker. Br Heart J 1995;74: 502-507.

29 Morello A, Lloyd-Jones DM, Chae CU, van Kimmenade RR, Chen AC, Baggish AL, O’Donoghue M, Lee-Lewandrowski E, Januzzi JL Jr: Association of atrial fibrillation and amino-terminal pro-brain natriuretic peptide concentrations in dyspneic subjects with and without acute heart failure: results from the ProBNP Investigation of Dyspnea in the Emergency Department (PRIDE) study. Am Heart J 2007;153:90-97.

30 Inoue S, Murakami Y, Sano K, Katoh H, Shimada T: Atrium as a source of brain natriuretic polypeptide in patients with atrial fibrillation. J Card Fail 2000;6:92-96.

-31 Savarese G, Musella F, D’Amore C, Vassallo E, Losco T, Gambardella F, Cecere M, Petraglia L, Pagano G, Fimiani L, Rengo G, Leosco D, Trimarco B, Perrone-Filardi P: Changes of natriuretic peptides predict hospital admissions in patients with chronic heart failure: a metaanalysis. JACC Heart Fail 2014;2:148-158. 